Pediatrics Jan 2002;109:116-123). (Reprints: Dr JK Lynch, Bldg 10, Room 5S220 10 Center Dr, MSC 1447, Bethesda, MD 20892).

COMMENT. The authors conclude that pediatric stroke registries, similar to the one in Canada, are needed to provide data regarding the impact of maternal and perinatal factors on the causes and outcome of childhood stroke in the US.

\title{
DEVELOPMENTAL DISORDERS
}

\section{X-LINKED LISSENCEPHALY WITH ABSENT CORPUS CALLOSUM}

Three new cases of the congenital syndrome consisting of X-linked lissencephaly, absent corpus callosum, and genital anomalies (XLAG) are reported from the University Hospital, Angers, France. Male sex, intractable epilepsy, hypotonia, and early mortality are additional characteristics. MRI findings include anterior pachygyria, posterior agyria, thickened cerebral cortex, dysplastic basal gangiia, and agenesis of the corpus callosum. Pathologically, the brain shows a trilayered cortex, neuronal migration defect, dysplastic basal ganglia, and gliotic and spongy white matter. Females related to affected boys may be mentally retarded, suffer from epilepsy, and have agenesis of the corpus callosum. (Bonneau D, Toutain A, Laquerriere A, et al. X-linked lissencephaly with absent corpus callosum and ambiguous genitalia (XLAG): Clinical, magnetic resonance imaging, and neuropathological findings. Ann Neurol March 2002;51:340-349). (Respond: Dr Bonneau, Sevice de Genetique Medicale, CHU d'Angers, 4 rue Larrey, 49100 Angers, France).

COMMENT. First described by Berry-Kravis and Israel in 1994, XLAG is characterized by lissencephaly, complete agenesis of the corpus callosum, and hypogenitalism. A posterior agyria, an anterior pachygyria, and an intermediate thickening of the cortex distinguish this syndrome from lissencephaly type I, in which the cortex is thicker, and the corpus callosum may be hypoplastic but not absent. The MRI and neuropathological features are also distinct. Abnormal MRI findings in carrier females also expand the XLAG phenotype.

\section{MYELOMENINGOCELES AND INCIDENCE OF SHUNTING}

The distribution of postnatally repaired myelomengocele (MMC) lesions, characterized by neurologic and radiologic assessment, and the incidence of shunting were determined and correlated by a retrospective chart review of 297 patients followed at the spina bifida clinic at the Children's Hospital of Philadelphia. The rate of ventricular shunting was $81 \%$, and was correlated with the level of the lesion. The more cephalad the MMC, the higher the incidence of shunting. Levels determined by functional neurologic examination were generally higher or equal to the vertebral level of the lesion defined by spine radiographs. Sacral lesions categorized radiologically rather than neurologically had a higher shunt rate. (Rintoul NE, Sutton LN, Hubbard AM, et al. A new look at myelomeningoceles: Functional level, vertebral level, shunting, and the implications for fetal intervention. Pediatrics March 2002;109:409-413). (Reprints: Leslie N Sutton MD, Division of Neurosurgery, Children's Hospital of Philadelphia, 34th St and Civic Center Blvd, Philadelphia, PA 10194).

COMMENT. In this series of patients, the proportion of lumbar MMC was $62 \%$ in contrast to $80 \%$ reported by Emery and Lendon in a study published in 1973 . The authors of the Philadelphia study comment that differences in the 